Delft University of Technology

\title{
An emotional deliberation approach to risk
}

Roeser, S; Pesch, U

DOI

10.1177/0162243915596231

Publication date

2016

Document Version

Accepted author manuscript

Published in

Science, Technology \& Human Values

\section{Citation (APA)}

Roeser, S., \& Pesch, U. (2016). An emotional deliberation approach to risk. Science, Technology \& Human Values, 41(2), 274-297. https://doi.org/10.1177/0162243915596231

\section{Important note}

To cite this publication, please use the final published version (if applicable).

Please check the document version above.

\section{Copyright}

Other than for strictly personal use, it is not permitted to download, forward or distribute the text or part of it, without the consent of the author(s) and/or copyright holder(s), unless the work is under an open content license such as Creative Commons.

\section{Takedown policy}

Please contact us and provide details if you believe this document breaches copyrights.

We will remove access to the work immediately and investigate your claim. 


\section{An Emotional Deliberation Approach to Risk}

\section{Introduction}

Risks arising from technologies raise important ethical issues. Although technologies can contribute significantly to human well-being, they can also introduce risks for people's wellbeing due to, for example, pollution and accidents, based on malfunctioning or human error. As a consequence of such side-effects, technologies can trigger emotions, including fear and indignation. Debates about risky technologies often result in conflicts and stalemates between experts and laypeople. Recent examples of fruitless, heated debates about risk concern Carbon Capture and Storage (CCS), shale gas, nanotechnology, genetic modification and nuclear energy. The question arises as to how we should deal with emotions in political decision making about risky technologies.

Emotions have often been met with suspicion in political debates about risky technologies, because they are seen as contrary to rational decision making. They are either ignored in deliberation about risks or they are taken as 'necessary evils' that have to be respected in a democratic society. For example, approaches to participatory risk assessment (PRA) invite the public to play a role in the debate, but they nevertheless treat public emotions as irrational states. Although it needs to be acknowledged that emotions can cloud our understanding and evaluation of evidence about risks, emotions can also provide invaluable insights that are overlooked in conventional, rationalist approaches to decision making about risk. Moral emotions, such as compassion and feelings of responsibility and justice, can play an important role in judging ethical aspects of technological risks, such as justice, fairness and autonomy (Roeser, 2006b, p. 208; 2009, 2010, 2011, 2012).

In this paper we discuss how emotions can be integrated into approaches for political decision making about risk. We first provide an overview of recent developments in emotion research and explain their relevance for decision making about risk (section 2). We then show that emotions do not play an explicit role in existing models for PRA (section 3). We argue that this is reflected in the underlying, rationalistic approaches to political philosophy, socalled deliberative democracy approaches (section 4). We propose to study alternative approaches in political philosophy and political theory that do explicitly endorse the importance of emotions (section 5). We then offer an 'emotional deliberation approach to risk,' a procedural approach for policy making that takes seriously emotional responses to technological risks and the ethical concerns that lie behind them (section 6). This approach provides recommendations for including emotions as an integral part of PRA. By 
incorporating moral emotions into PRA, this approach allows for morally better political decisions about risky technologies and a better understanding between experts and laypeople (section 7). Doing so makes an important contribution in a context where democratic decision making can easily be overshadowed by technocratic approaches.

\section{Emotions and Risk Ethics}

Debates about risky technologies are often fierce and emotional, resulting in stalemates between opponents and proponents. The proponents can often be found amongst the experts, who point to scientific studies that show that a technology is safe. The opponents can often be found amongst the public, who usually do not have the same access to scientific knowledge, nor the authority to make scientific claims. Typically, the views of the public get dismissed as they are said to be uninformed, emotional and not capable of rational understanding of technological risks (Sunstein 2005 defends this position). Others argue that although people are emotional and hence supposedly irrational in their risk perceptions, one has to include their views for democratic reasons (Loewenstein, Weber, Hsee, \& Welch, 2001). Other scholars have argued that one should use the risk emotions of the public instrumentally, in order to create acceptance for a technology (De Hollander \& Hanemaaijer, 2003).

There are democratic as well as substantive reasons to include the considerations of stakeholders in decision making about risk. As argued by many scholars, risk is not only a quantitative notion; rather, it also involves ethical considerations that are insufficiently addressed in conventional, quantitative methods for risk assessment, such as cost-benefit analysis (Fischhoff, Lichtenstein, Slovic, Derby, \& Keeney, 1981; Jaeger, Webler, Rosa, \& Renn, 2013; Krimsky \& Golding, 1992; Shrader-Frechette, 1991; Slovic, 2000). Trade-offs between risks and benefits are unavoidable when judging the moral acceptability of risky technologies. There are no risk-free options; rejecting technology also entails risks (Sunstein, 2005). For example, a house can collapse, but without a house there would be no shelter. Ideally, we try to maximize the benefits and minimize the risks of a technology. However, even if we try to minimize risks, we can never rule them out completely. And when risks are present, it is not clear how we should balance them against benefits. As critics of cost-benefit analysis have emphasized, we also need to include qualitative or ethical considerations such as justice, fairness and autonomy (cf. e.g. Shrader-Frechette 1991, contributions to Asveld and Roeser 2009). These considerations also play a major role in laypeople's risk perceptions, 
which has led Paul Slovic to argue that laypeople have an alternative rationality that is equally important and legitimate as that of experts (Slovic, 2000).

Paul Slovic and colleagues have also conducted empirical studies that show that emotions are a major determinant in risk perception. They call this the 'affect heuristic' or 'risk as feeling' which they argue needs to be corrected by 'risk as analysis' or formal approaches to risk (Alhakami \& Slovic, 1994; Finucane, Alhakami, Slovic, \& Johnson, 2000; Slovic, 1999; Slovic, Finucane, Peters, \& MacGregor, 2002). This means that the previously mentioned reasons to include public views of risk are challenged by the finding that these views are based on emotions. This is due to a common view of the relationship between reason and emotion according to which supposedly irrational emotions need to be corrected by reason. For example, the dominant view in the risk perception literature is that reason and emotion are distinct faculties. This approach, often called Dual Process Theory (DPT), has been developed in empirical decision theory and cognitive psychology (cf. Epstein, 1994; Greene \& Haidt, 2002; Haidt \& Graham, 2007; Sloman, 1996, 2002; Stanovich \& West, 1998; see Kahneman 2011 for a popularized overview of his own groundbreaking work and that of other scholars in this field). According to DPT our mind works via two distinct systems, namely system 1 which is fast, intuitive but unreliable, and system 2 , which is rational, analytical and reliable but also slow and demanding significant effort and attention and for that reason prone to be 'lazy' in many people. Many defenders of DPT take it that emotions are part of the fast yet unreliable system 1, and reason or analytical rationality are considered to fall under the reliable but slow system 2. For example, Jonathan Haidt (2001) has argued that while we think that we are rational moral agents, our moral thinking is actually governed by 'irrational emotions and gut reactions,' echoing David Hume's famous dictum that 'reason is, and ought to be, the slave of the passions' (Hume 2007/1739-1740).

However, there is reason to question this strict dichotomy between reason and emotion. In the last decades emotion scholars from philosophy and psychology have argued that emotions are a form of practical rationality (Damasio, 1994). They have developed so-called cognitive theories of emotions, arguing that emotions have affective as well as cognitive aspects (psychologists: e.g. Scherer et al. (1984), Frijda (1986), Lazarus (1991), philosophers: e.g. de Sousa (1979), Greenspan (2014), Blum (1994), Little (1995), Stocker (1996), Goldie (2000), Ben-Ze'ev (2001). Several philosophers interpret emotions as judgments of value (Nussbaum, 2001; Roberts, 2003; Solomon, 1993; Zagzebski, 2003; Roeser \& Todd, 2014).

In contrast with the dichotomous approach to reason and emotion that is dominant in risk perception research, this cognitive theory of emotions provides for the idea that risk emotions 
are not irrational but an important source of insight into what people value (Bandes, 2008; Kahan, 2008; Slovic, 2010b; Slovic, Finucane, Peters, \& MacGregor, 2004). Risk emotions are necessary in order to grasp the previously mentioned ethical aspects of risk (Roeser, 2006b, 2010, 2012). Moral emotions such as indignation, guilt, sympathy and feelings of responsibility can help us be aware of important moral values such as justice, fairness and autonomy. Emotions can then be seen as a major source of insight into ethical considerations in decisions about acceptable risk (Roeser, 2006b).

Yet, these considerations do not lead to clear-cut policy guidelines, as by their very nature, well-grounded ethical judgments have to take into account context-specific features (Broad, 2014; Dancy, 2004; Ewing, 1929; Prichard, 1912; Ross, 1939). Emotions are necessary for context-sensitive ethical judgments (Damasio, 2003; Roeser, 2006a). Furthermore, risk emotions often concern highly contested issues, such as fear concerning nuclear energy, fracking or genetic modification. When it comes to context-sensitive judgments and controversial issues, a participatory approach to political decision making is best suited, as it can incorporate important ethical considerations from all stakeholders (Dryzek, 1994; Jaeger et al., 2013; Pesch, 2014; cf. Shrader-Frechette, 1991). However, existing participatory approaches to risk have not focused on emotions, as we show in the following section.

\section{The Neglect of Emotions in Participatory Risk Assessment}

Technological risks give rise to issues that pertain to the domain of politics (Jasanoff, 2003, p. 225), by being intrinsically normative. Möller (2012) analyzes risk as a so-called 'thick concept,' i.e. a concept that is descriptive and normative at the same time. This means that decision making about technological risks requires more "transparent, deliberative, and inclusive processes of informing policy and decisions" (Owens, Rayner, \& Bina, 2004, p. 1944 ) and the inclusion of 'cultural rationality' (Krimsky, 1986; Krimsky \& Plough, 1988) in order to overcome the political inadequacy of dominant quantitative forms of decisionmaking. To accommodate this requirement, a large number of participatory methods have been developed and applied in different fields of policy-making since the 1960s. In the context of risk, these methods can be referred to under the heading of 'Participatory Risk Assessment' (PRA in short). PRA approaches are based on the idea that it is important to include the public in decision making trajectories on technological risks in order to make these trajectories more democratic (also see Fischer, 1999; Funtowicz \& Ravetz, 1993; Jasanoff, 1998; Ravetz, 1996; Rowe \& Frewer, 2000). Furthermore, including the public can contribute to decision making by attending to the knowledge people have of the societal 
context that might be affected by technological risks (Wynne, 1992). Including the public also avoids a purely technocratic way of decision making, by paying attention to moral values that people find important and that need to be taken into account in decision making about acceptable risk (Krimsky \& Golding, 1992; Lichtenstein, Slovic, Fischhoff, Layman, \& Combs, 1978; Slovic, 2000; Asveld \& Roeser 2009).

A wide range of participatory methods and tools has been developed and classified that allows the direct involvement of citizens in forms of collective decision-making (Cuppen, 2009; Fiorino, 1990; Van Asselt \& Rijkens-Klomp, 2002). Here is an overview of the most popular methods that can be identified:

- Focus groups are planned discussions among a small group of stakeholders facilitated by a moderator and designed to obtain information about preferences and opinions.

- $\quad$ Scenario analysis is an interactive process engaging a group in a creative process of identifying key issues, creating and exploring scenarios to learn about the external environment and/or integrating the insights into the decision-making of an organization.

- Policy exercises are creative processes in a gaming atmosphere in which a heterogeneous group of participants synthesizes and assesses knowledge from various sources and in which ideas or policy options can be explored.

- Participatory modelling refers to the active involvement of model-users in the modelling process.

- $\quad$ Citizens' juries are a means for obtaining informed citizen input on policy decisions.

- Consensus conferences are public enquiries involving a group of citizens who are charged with the assessment of a socially controversial topic of science and technology.

In spite of the variety of approaches, and the discourse on democratization, there have been authors who claim that these approaches rely too much on an instrumental and technocratic framework, focusing on analytical-rational aspects of participation at the expense of emotional aspects (Engdahl \& Lidskog, 2014; Harvey, 2009; Hoggett \& Thompson, 2002). Indeed, advocates for public participation usually frame their work in terms of cognitiveanalytical attributes such as 'social learning,' 'local knowledge,' and 'lay expertise' (Fischer, 1999; Garmendia \& Stagl, 2010; Irwin, 1995; Van de Kerkhof \& Wieczorek, 2005; Wynne, 
1992), while emotions are neglected, regardless of their role in lay people's risk perceptions (Slovic, 2010a). One could broaden the interpretation of notions such as learning, knowledge and expertise by acknowledging the importance of emotions for moral learning, knowledge and expertise. However, approaches to PRA do not explicitly address the role and potential contribution of emotions. So, despite the elaborate effort for developing participatory methods and accompanying evaluative frameworks, the role of emotions is still hardly addressed in the literature and practice of PRA approaches. As Hoggett and Thompson (2002, p. 107) claim: "either the emotions are ignored or, if they are mentioned, it is only as dangerously destabilizing forces that need to be kept in check." This exclusion of emotions may be unintentional, but the net result is that the negative appraisal of emotions that is pervasive in technocratic approaches is reproduced. This implies that PRA-methods are in accordance with the dichotomous view of reason and emotion that also characterizes the approaches to risk discussed in the previous section. This means that moral values are not sufficiently addressed, and that not all stakeholders and their perspectives are heard and respected.

This can be illustrated by a recent example from the Netherlands concerning the highly controversial plan to locate Carbon Capture and Storage (CCS) in the city of Barendrecht. When two Dutch ministers attended a local debate about CCS, they sat on stage and told the audience at the beginning of the meeting that it did not really matter what they would say, as the decisions had already been made anyway. The audience was furious, and the debate was a hostile event, ultimately leading to a withdrawal of the plan. Moral concerns about the just distribution of risks and benefits, and the feeling of not being taken seriously, were not merely neglected but explicitly discarded, intensifying the divide between institutional actors and the local population. Afterward, another intended region in the Netherlands, Groningen, has refused to accept CCS, saying that they did not want to be the 'drain of the Netherlands' (cf. Cuppen, Brunsting, Pesch, \& Feenstra, fortchoming, for an analysis of this case).

However, a more balanced understanding of emotions as a source of deliberation is necessary to allow the full effectuation of participatory methods as a source of empowerment and democracy. MacKuen et al. (2010, p. 441) argue that taking emotions seriously is important because different sorts of emotions can come into play, each having major consequences for the openness of an individual to constructively partake in processes of political decision-making. Furthermore, as argued in the previous section, moral emotions can contribute to well-grounded insights into whether a technological risk is morally acceptable or not. For example, enthusiasm for a technology can point to benefits to our well-being, whereas fear and worry can indicate that a technology is a threat to our well-being; sympathy 
and empathy can give us insights into a fair distribution of risks and benefits, and indignation can be an indication of violations of autonomy by technological risks that are imposed on us against our will (cf. Roeser, 2006b, 2012). In other words, there is no reason to exclude the emotions of the public from decision making processes in case of risky technologies; to the contrary, these emotions are crucial to come to a well-grounded moral assessment. However, as we have shown, existing approaches to PRA do not explicitly address emotions.

\section{Rationalist Biases in Political Theories Underlying PRA}

The negligence or even hostility towards emotions in PRA approaches may find its root in the way these approaches are related to the literature on deliberative democracy. This deliberative account of democracy means that democratic decisions ought to be the outcome of the exchange of moral reasons between citizens, which presupposes the participation of citizens (Bohman \& Rehg, 1997; Gutmann \& Thompson, 2000; Habermas, 1996). However, just as theorists of deliberative democracy speak about participation, but not about participatory methods, authors on participatory methods speak about deliberation, but fail to speak about deliberative democracy (cf. Huitema, Van de Kerkhof, \& Pesch, 2007). Having said that, PRA can still be framed as part of the so-called 'deliberative turn' in democratic theory, in which deliberation relates to debate and discussion aimed at producing reasonable, well-informed opinions in which participants are willing to revise their preferences and views in light of discussion, new information, and claims made by fellow participants (Chambers, 2003, p. 309).

The close connection between PRA and approaches to deliberative democracy is also reflected in their emphasis on rationality. We showed in the previous section that PRAs unduly neglect emotions. Similarly, O’Neill (2002) argues that approaches to deliberative democracy are overly rationalistic and should include emotions as sources of moral knowledge. The literature on deliberative democracy usually presumes participants who are to apply disengaged forms of reasoning in which they have to take on the standpoint of the 'generalized other,' meaning that they have to abstract from their individuality and concrete needs, desires, and emotions (Benhabib, 1985, p. 411). This reflects a view of reason that is divorced from the emotions, passions and appetites that move us (also see Bradshaw, 2008; Rorty, 1989). Rationalist approaches in political philosophy overlook that the ability to be moved allows political action in the first place. As critics of rationalist approaches argue, without an affective appraisal of public affairs there would be no democracy. Seen from that light the exclusion of emotions is an inherently anti-political idea, that de facto only allows 
the political empowerment of people that are trained to frame their affectively based deliberations in such a way as to comply with disengaged rationality. People who have not been trained as such, for example working class communities, are therefore excluded beforehand from participating in deliberative democracy (Hoggett \& Thompson, 2002). Furthermore, the exclusion of emotion in political deliberation is dubious given the important role emotions can play in pointing out what we value (Nussbaum, 2013; Roeser \& Todd, 2014).

The neglect of emotions in the literature on deliberative democracy appears to be reproduced in the literature on PRA, by being based on an analytical, disengaged approach to rationality. In order to live up to its ideals of empowering people as full citizens, it would be more adequate to encourage processes that are based on a communicative rationality, which is "oriented towards intersubjective understanding, the coordination of actions through discussion, and the socialization of the members of the community" (Dryzek, 1994, p. 14). As we will argue in what follows, emotions can make a crucial contribution to such a communicative rationality. In order to live up to their democratic ideals, PRA approaches should designate a substantial role to the emotions. This implies that in order to be welcoming to the emotions, the theoretical grounding of participatory methods requires alternative approaches to democracy, in which the emotions are given due attention.

\section{5. 'Emotion-friendly' Approaches in Political Theory and their Relevance for PRA}

In the previous section we have discussed how the lack of attention for emotion in PRA can be traced back to a dismissal of emotions in the underlying approaches to political philosophy, namely deliberative democracy approaches. In this section we will take a closer look at alternative theories in political philosophy that have identified this lack of attention for emotions as a weakness and propose a more important role for emotions. We will then proceed in section 6 to develop an approach to PRA that builds on these alternative accounts in political philosophy and explicitly acknowledges emotions.

In general we can observe that a dismissal of emotions in political philosophy is based on an understanding of emotions as irrational or a-rational states that undermine or threaten sound decision making. However, various political theorists highlight the importance of emotions for moral knowledge, reflection and understanding, based on a richer accounts of emotions (Hall, 2005; Kingston, 2011; Kingston \& Ferry, 2008; Marcus, 2000, 2010; Neuman, Marcus, Crigler, \& MacKuen, 2007; Nussbaum, 2013; Staiger, Cvetkovich, \& Reynolds, 2010). 
Cheryl Hall (2005) emphasizes that paying attention to emotions in politics is important, as emotions provide us with a better understanding of the perspective of others:

'Sooner or later, that which is ignored, silenced, rejected or repressed will return. In contrast, acknowledging the dissonance, exploring it, and learning as much as possible from the different voices provides more chance of genuinely moving to a new position. [...] citizens who can work with their passions will be better able to develop their own perspectives as well as be more receptive to the perspective of others.' (p. 130)

It is a commonly accepted idea that in order for democracy to work, people's reason needs to be educated. Drawing on work by Plato, Rousseau and contemporary feminist scholars, Hall argues that next to this, people's emotions need to be educated. She emphasizes that this does not mean manipulating people and their emotions, although she acknowledges that this is a possible danger. Rather, she argues that educating passions in the right way means enabling people to construct and change their passions or emotions. Based on the cognitive theory of emotions that we endorse, one can see that emotions can be both the subject and the object of critical reflection. For example, Michael Lacewing (2005) elaborates on how second-order emotions, i.e. how we feel about our emotions, can help us to critically reflect on and deliberate about our first order-emotions. Nussbaum (2001) argues that emotions can help us to understand the perspective of others. Hall argues that we should educate people in such a way that they develop a 'passion for democracy' (Hall, 2005, pp. 131-133). This will enable people to engage with other people's perspectives, and it will motivate them to actively participate in democratic processes.

Rebecca Kingston (2011) reasons in a similar vein, by arguing that attention to the emotions is necessary for good citizenship:

'Attention to and care for the disposition and the tone through which we engage other citizens is essential for an ongoing practice of good citizenship' (p. 208).

She proposes to adopt a broader approach to political deliberation that makes room for emotions and what she calls 'public passion':

Integrating an understanding of public passion into normative political theory will lead us to recognize a much wider sphere for political deliberation than before. This broadened 
sphere will include the realms of artistic expression through a number of media, and will allow for more multiple forms of exchange and debate than the traditional giving and receiving of arguments. It will involve a heightened sensitivity to the multiple manifestations of political communication (p. 209).

Kingston's approach requires that the range of accepted forms of expression should be significantly broadened as compared to the conventional discourse that is dominated by an analytical paradigm of rationality. Conventional political discourse is mainly limited to presentation of empirical data and deductive argumentation in which underlying values are often not explicitly acknowledged. By broadening the range of accepted forms of expression, political deliberation can more explicitly acknowledge important values and emotions, and it becomes more accessible for a wider range of audiences who might not have (sufficient) access to these conventionally accepted sources of knowledge and reflection.

This account of deliberation is based on an Aristotelian version of republicanism and focuses on the active life that expresses the human virtues, intelligence, character and feelings (Bradshaw, 2008, p. 173). In other words, for such approaches emotions become an intrinsic element of deliberation, not only for virtuous individuals, but also for virtuous citizens who participate in the processes of collective decision-making. Actively taking part in a political community requires an affective bond (Pesch, 2005, p. 58; Taylor, 1995, pp. 187-188) by caring about our fellow citizens and their well-being.

However, we wish to emphasize that public passion and care for others can expand beyond one's own tight community to encompass humanity. Nussbaum (2001) calls this 'expanding our circle of concern.' Taking on a universalistic perspective is not the prerogative of rationalism, but also requires sympathy and care, as has been argued already in the $19^{\text {th }}$ century by William Whewell (1845). Indeed, people are able to care for people who live far away, as long as their destinies are presented in a way that entices emotions (cf. Slovic 2010b for empirical evidence). This is especially important in the context of technological risks, as they frequently transcend borders of countries, space and time. Furthermore, emotional responses to risky technologies are especially fierce given the scientific and moral complexities involved. At the same time, emotions can make a major contribution to genuinely democratic procedures of decision making in a context where technocratic approaches are all too tempting.

\section{How to Integrate Emotions in PRA: An Emotional Deliberation Approach to Risk}


In the previous section, we have discussed insights from approaches to political philosophy that argue for an important role for emotions in politics. These ideas can be extended to political decision making about risky technologies (cf. Harvey, 2009). In this section we will elaborate on how PRA can be reformed in the light of these insights. We propose to adjust PRA approaches in order to explicitly address emotions. We will sketch the contours of a procedural approach to 'emotional deliberation' about risks that explicitly encourages and includes moral emotions as indispensable sources of ethical insight. It can be used as a standalone approach but it can also be integrated into existing PRA methods.

Technological risks can have profound effects on people's wellbeing and values, and this should be explicitly addressed in PRA. Science-based information and technical expertise are necessary prerequisites in decision making about technological risk, but they are not sufficient, because they do not as yet provide for moral argumentation, which requires reflection on values, norms, virtues and ideals. This is where emotions can serve as an invaluable source of insight and deliberation in PRA. Emotions can provide important moral insights via care, sympathy, empathy and compassion and feelings of responsibility, justice and indignation. Emotions help us to reflect on which values we find important, how our actions relate to our lives and those of others, and allow us to care for the wellbeing of others. PRA should encourage emotional deliberation about which role technologies can and should play, and under which conditions, in order to contribute to people's wellbeing now and in the future, and to realize important values such as justice, fairness, equity and sustainability. In order to be both effective and legitimate, participatory methods of risk assessment should include attention to the full range of human reflection and deliberation, which means including emotions as an irreplaceable source of moral insight.

In the light of these ideas, we propose to revise approaches to PRA by paying attention to the following considerations:

\section{Symmetrical risk communication}

Risk communication experts often use an asymmetrical approach, with a sender and a receiver. However, the dominant approach to communication in political philosophy is based on Habermas's (1985) 'machtsfreie Dialog,' a symmetrical, egalitarian way to exchange ideas. This should also be applied to risk communication as a basis for genuinely democratic deliberation and decision making about risks. Risk communication should not only be about sending, but also about receiving, listening to each other and exchanging views. However, by framing discussions about risk in a rationalistic way, as is usually the case, not all 
stakeholders are taken equally seriously. Emotionally framed concerns are easily dismissed without further discussion. Instead, an emotional deliberation approach to risk pays explicit attention to people's emotions. It invites emotions, narratives and the imagination into the arena of deliberation, in order to include all relevant stakeholders and values.

\section{Create symmetric setups of discussions}

In conventional debates about risky technologies, the hierarchy between experts and laypeople is exemplified in an asymmetrical setting where the experts are placed prominently on stage and the public forms an anonymous audience. In such a setting, it can be awkward for people to express their emotions, as the experts, who usually frame their contributions in a scientific and rationalist way, dominate the discourse. Instead, all participants should be placed on an equal footing to encourage a sense of equality and empowerment for layparticipants. In the case of small groups this can be done by round table discussions. In the case of larger audiences, discussion leaders and panelists can create an interactive atmosphere by asking questions to the audience and noting ideas of the audience on visual display, such as a smartboard.

III. Talk about values

It is important that values are explicitly addressed in discussions about risky technologies. However, as experts tend to dominate the discourse, it is likely that the discussion will center on scientific evidence, excluding moral concerns, which are particularly vivid amongst laypeople (cf. Slovic 2000 for empirical studies that show this). Instead, talking about values should be of utmost concern in public debates about risky technologies, as this is what the democratic decision making should be about.

\section{Talk about emotions}

Emotions are usually dismissed or not taken seriously in public debates. At most, authorities say things as 'I understand or respect your emotions, but rationally/scientifically you are not correct.' Rather, one should ask what people are emotional about, especially when emotions persist in light of scientific evidence. This might indicate that the emotional concerns are about other issues than the scientific facts. Most likely, emotions are about values. Talking about emotions can make a crucial contribution to a debate about risky technologies as they reveal values, moral reasons and considerations that can get overlooked when emotions are not explicitly addressed. For example, the fear of a new technology might indicate that one is 
not convinced of the safety measures or the supposed advantages of the technology that might make it acceptable to run small risks. Persisting emotions might also be an indication of a lack of trust in authorities, which should be addressed rather than dismissed, in order to create an open, transparent conversation. Dismissing emotions can be seen by people as a signal that their lack of trust might be justified. Evading an explicit discussion of a lack of trust can come across as fear and a sign that one has something to hide. Openly discussing a lack of trust instead signals respect, and a willingness to engage in critical self-reflection, which is an important ingredient of genuine trustworthiness. Here is a major role for moderators of discussions, by enticing people to articulate the values, reasons and considerations that underlie their emotions.

\section{Ask questions}

In case people respond emotionally in debates, they are often told off by debate leaders and asked to be rational. On our proposed approach instead, emotions are seen as important cues to issues that matter to people and should hence be explicitly addressed. So instead of dismissing emotions, debate leaders or other participants should encourage people to express the concerns underlying their emotions. Asking questions can be a powerful tool. Discussion leaders should invite people to tell narratives and talk about their emotions. Possible questions to trigger such conversations are:

\section{'What are you afraid of?'}

'Under what conditions would you be less worried?'

'Can you understand the viewpoint of the person from the other group?'

'If you were in charge, how would you solve this problem?'

Such questions can encourage people to express the concerns and values underlying their emotions, and to critically reflect upon one's own emotions and those of others, by also putting oneself in the shoes of another person (for a more extensive list of questions, see Nihlén Fahlquist and Roeser 2014).

VI. Have a dialogue among all people

In most debates on risks which involve the general public, the discussion is dominated by the experts and directed by a debate leader. However, it can be very fruitful to let people in the audience or at a round table respond to each other and to share or criticize each other's views, 
arguments or emotional responses. This encourages ways to think 'out of the box,' as a possibly surprising point of view can be explored by various participants to the deliberation. It can also be more forceful if people in the audience correct each other's possibly biased opinions and emotions than if the experts or debate leaders do this. More in general, this contributes to a symmetrical, 'power-free' dialogue. Of course a debate leader can intervene if people are disrespectful to each other, or if someone dominates the debate, and experts can provide scientific information if that makes a constructive contribution to the exchange. But experts and debate leaders should dose their contributions carefully as not to hamper an engaging dialogue.

\section{Convey respect}

The typical asymmetrical setup of many public debates on risk signals a hierarchy, with the expert being valued more than the lay audience. However, this can convey a lack of respect. The people in the audience may lack the specific scientific expertise of the expert, but first of all, they bring in different forms of expertise, based on their profession or their role in society. Given the complexity of many decisions about risky technologies, such additional perspectives can prove to be valuable, by drawing attention to contextual factors that experts might not include. Furthermore, decision making about risky technologies does not only involve science, but also moral norms and values. In a democratic society, we should encourage all citizens to bring in their views and moral norms and values and related emotions. Here, all citizens are prima facie on equal footing. Hence, experts and debate leaders should communicate in a respectful, dignified, way, and allow an equal playing field.

\section{Have a clear procedure}

In order to ensure a safe and constructive setting, it should be clear to the audience what the procedure is: what happens with their input, when and how. Furthermore, the outcome of the procedure should be genuinely open. In other words, it should not be a fake consultation with preset arrangements, as in the previously mentioned example concerning CCS in Barendrecht, where the ministers told the local population at the beginning of a public debate that the decisions were already made. Arguably, in the end the emotional response of the public was not only about the risks of CCS but about a procedure that was conceived of as unfair, undemocratic and disrespectful. Hence, rather than being a safe strategy, conveying to the public that they have no influence can backfire (Cuppen, Brunsting, Pesch, \& Feenstra, Fortchoming). An open debate, with respect for people's views and emotions, is explicitly 
uncertain about the outcomes, but might actually be more fruitful and effective, as well as being more genuinely democratic.

These considerations can be seen as guidelines for 'emotional deliberation' on risky technologies. Note that several of these considerations also figure explicitly or implicitly in PRA approaches, however, in those approaches the contribution the emotions can make is not acknowledged, as we have argued in section 3. Public decision making about risky technologies should include the moral emotions of the public, politicians, and also experts. Emotions should not be neglected or seen as 'givens' that cannot be investigated any further, as is the case with conventional technocratic or PRA approaches. Rather, emotions should be seen as triggers for discussion. The arguments, reasons, values and other moral considerations that are revealed by or lie behind emotional responses to technological risks and benefits have to be taken seriously.

\section{Conclusion: Evaluating the Promise of an Emotional Deliberation Approach to Risk}

In this paper we have argued that conventional PRA approaches are overly rationalistic, by being based on equally rationalistic approaches in political theory, which in turn are based on a dichotomous view of reason and emotions. This dichotomous view of reason and emotion has been rejected or nuanced by many emotion scholars. Their alternative approaches allow for a different political theory that gives emotions an important role in the public debate. Based on such approaches, we have developed a sketch for a new approach to PRA, an emotional deliberation approach to risk, in which emotions are a key source of reflection and deliberation on important values in decision making about risks.

This new approach requires debate leaders and experts to rethink their usual approaches to debates about risky technologies. Fiorino (1989) has argued that public participation in risk assessment leads to procedurally, substantially and instrumentally better decisions. Our proposed emotional deliberation approach complies more strongly with these three considerations. The approach that we propose is procedurally more fair and just, as it allows all stakeholders to express all important values in an accessible way, by giving their emotions an explicit role. This also allows for substantially better decisions, as emotions are an important source of moral insights that are not included in conventional, technocratic approaches to risk and in traditional PRA, as these approaches are based on an overly rationalistic ideal of deliberation. On an emotional deliberation approach to PRA, it can be expected that people will be more willing to accept the outcome of the deliberation, as they 
will feel that they have been respected and heard. Hence, the emotional deliberation approach has as a side effect that it is also instrumentally better in achieving more constructive decision making than approaches that aim primarily at consensus, without really respecting people's moral views and emotions, as is the case in traditional, asymmetric approaches to risk communication that strive for support as a goal in itself. Public support should be a welcome by-product of a fair and convincing procedure, but not something that is a primary aim that is aspired for at all costs, as is often the case in conventional approaches to risk communication and deliberation.

Hence, we believe that it is worthwhile to implement and further develop an 'emotional deliberation approach' to risk, as it is more fair, leads to morally better decisions and is likely to be more effective. It is based on a more sophisticated and nuanced view on emotions and their role in political decision making. The traditional and dominant dichotomy between reason and emotion is overly simplistic, and it is democratically harmful. It is time to move towards a new paradigm that gives emotions a central role in critical reflection and deliberation about risky technologies. Decision making about risky technologies is too important to be investigated by a limited realm of human capacities and a select group of people. Rather, it concerns all of us, with all our ways in which we experience and assess a more and more complex world.

\section{Literature}

Alhakami, A. S., \& Slovic, P. (1994). A psychological study of the inverse relationship between perceived risk and perceived benefit. Risk Analysis, 14(6), 1085-1096.

Asveld, L., \& Roeser, S. (2009). The ethics of technological risk. London: Routledge/Earthscan.

Bandes, S. (2008). Emotions, values, and the construction of risk. Pennsylvania Law Review PENNumbra, 156, 421.

Ben-Ze'ev, A. (2001). The subtlety of emotions. Boston: MIT Press.

Benhabib, S. (1985). The Generalized and the Concrete Other: The Kohlberg-Gilligan Controvers and Feminist Theory. Praxis international(4), 402-424.

Blum, L. A. (1994). Moral perception and particularity. New York: Cambridge University Press.

Bohman, J., \& Rehg, W. (Eds.). (1997). Essays on Reason and Politics: Deliberative Democracy. Boston: MIT Press. 
Bradshaw, L. (2008). Emotions, Reasons, and Judgments. In R. Kingston \& L. Ferry (Eds.), Bringing the Passions Back In. The Emotions in Political Philosophy. (pp. 172-188). Vancouver and Toronto: UBC Press.

Broad, C. D. (2014). Five types of ethical theory. London: Routledge \& Kegan Paul Ltd.

Chambers, S. (2003). Deliberative democratic theory. Annual Review of Political Science, 6(1), 307-326.

Cuppen, E. (2009). Putting Perspectives into Participation. Constructive Conflict Methodology for Problem Structuring in Stakeholder Dialogues. Oisterwijk: Boxpress.

Cuppen, E., Brunsting, S., Pesch, U., \& Feenstra, C. (Fortchoming). Seeing things differently: the role of frames in societal debate on a carbon and capture storage project in the Netherlands. Environment and Planning A.

Damasio, A. (2003). Looking for Spinoza: Joy, Sorrow, and the Feeling Brain. Orlando: Harcourt.

Damasio, A. R. (1994). Descartes' error: Emotion, rationality and the human brain. New York Putnam.

Dancy, J. (2004). Ethics without principles. Oxford: Oxford University Press.

De Hollander, A., \& Hanemaaijer, A. (2003). Coping rationally with risks. RIVM rapport, 251701047.

Dryzek, J. S. (1994). Discursive democracy: Politics, policy, and political science. Cambridge: Cambridge University Press.

Engdahl, E., \& Lidskog, R. (2014). Risk, communication and trust: Towards an emotional understanding of trust. Public Understanding of Science, 23(6), 703-717.

Epstein, S. (1994). Integration of the cognitive and the psychodynamic unconscious. American psychologist, 49(8), 709.

Ewing, A. (1929). The Morality of Punishment. London: K. Paul Trench.

Finucane, M. L., Alhakami, A., Slovic, P., \& Johnson, S. M. (2000). The affect heuristic in judgments of risks and benefits. Journal of behavioral decision making, 13(1), 1-17.

Fiorino, D. J. (1989). Environmental risk and democratic process: a critical review. Colum. J. Envtl. L., 14, 501.

Fiorino, D. J. (1990). Citizen participation and environmental risk: A survey of institutional mechanisms. Science, Technology \& Human Values, 15(2), 226-243.

Fischer, F. (1999). Technological deliberation in a democratic society: the case for participatory inquiry. Science and Public Policy, 26(5), 294-302. 
Fischhoff, B., Lichtenstein, S., Slovic, P., Derby, S. L., \& Keeney, R. L. (1981). Acceptable risk. Cambridge: Cambridge University Press.

Frijda, N. H. (1986). The emotions. Cambridge: Cambridge University Press.

Funtowicz, S. O., \& Ravetz, J. R. (1993). Science for the post-normal age. Futures, 25(7), 739-755. doi: 10.1016/0016-3287(93)90022-1

Garmendia, E., \& Stagl, S. (2010). Public participation for sustainability and social learning: Concepts and lessons from three case studies in Europe. Ecological Economics, 69(8), 1712-1722. doi: 10.1016/j.ecolecon.2010.03.027

Goldie, P. (2000). The emotions: A philosophical exploration. Oxford: Oxford University Press.

Greene, J., \& Haidt, J. (2002). How (and where) does moral judgment work? Trends in cognitive sciences, 6(12), 517-523.

Greenspan, P. S. (2014). Emotions and reasons: An inquiry into emotional justification. New York and London: Routledge.

Gutmann, A., \& Thompson, D. (2000). Why deliberative democracy is different. Social Philosophy and Policy, 17(01), 161-180.

Habermas, J. (1985). The theory of communicative action: Volume 2: Lifeword and system: A critique of functionalist reason (Vol. 2). Boston: Beacon press.

Habermas, J. (1996). Three Normative Models of Democracy. In S. Benhabib (Ed.), Democracy and Difference. Contesting the Boundaries of the Political (pp. 189-208). Princeton: Pricneton University Press.

Haidt, J. (2001). The emotional dog and its rational tail: a social intuitionist approach to moral judgment. Psychological review, 108(4), 814.

Haidt, J., \& Graham, J. (2007). When morality opposes justice: Conservatives have moral intuitions that liberals may not recognize. Social Justice Research, 20(1), 98-116.

Hall, C. A. (2005). The trouble with passion: Political theory beyond the reign of reason: Routledge.

Harvey, M. (2009). Drama, talk, and emotion omitted aspects of public participation. Science, Technology \& Human Values, 34(2), 139-161.

Hoggett, P., \& Thompson, S. (2002). Toward a Democracy of the Emotions. Constellations, 9(1), 106-126.

Huitema, D., Van de Kerkhof, M., \& Pesch, U. (2007). The nature of the beast: are citizens' juries deliberative or pluralist? Policy Sciences, 40(4), 287-311. 
Hume, D., (2007/1739-1740), A Treatise of Human Nature, Edited by David Fate Norton and Mary J. Norton, Oxford: Oxford University Press.

Irwin, A. (1995). Citizen Science. A Study of People, Expertise and Sustainable Development. London: Routledge.

Jaeger, C. C., Webler, T., Rosa, E. A., \& Renn, O. (2013). Risk, uncertainty and rational action: Routledge.

Jasanoff, S. (1998). The political science of risk perception. Reliability Engineering \& System Safety, 59(1), 91-99.

Jasanoff, S. (2003). Technologies of humility: citizen participation in governing science. Minerva, 41(3), 223-244.

Kahan, D. M. (2008). Two conceptions of emotion in risk regulation. University of Pennsylvania Law Review, 741-766.

Kahneman, D. (2011). Thinking, fast and slow. New York: Macmillan.

Kingston, R. (2011). Public passion: rethinking the grounds for political justice (Vol. 54). Kingston: McGill-Queen's Press.

Kingston, R., \& Ferry, L. (2008). Bringing the passions back in: The emotions in political philosophy. Vancouver: UBC Press.

Krimsky, Sheldon. "Research under Community Standards: Three Case Studies." Science, Technology \& Human Values 11, no. 3 (1986): 14-33.

Krimsky, Sheldon, and Alonzo Plough. Environmental Hazards: Communicating Risks as a Social Process: Auburn House Dover, MA, 1988.

Krimsky, S., \& Golding, D. (1992). Social theories of risk. Westport: Praeger publishers. Lacewing, Michael. "Emotional Self-Awareness and Ethical Deliberation." Ratio 18, no. 1 (2005): 65-81.

Lazarus, R. S. (1991). Emotion and adaptation. New York: Oxford University Press.

Lichtenstein, S., Slovic, P., Fischhoff, B., Layman, M., \& Combs, B. (1978). Judged frequency of lethal events. Journal of experimental psychology: Human learning and memory, 4(6), 551.

Little, M. O. (1995). Seeing and caring: The role of affect in feminist moral epistemology. Hypatia, 10(3), 117-137.

Loewenstein, G. F., Weber, E. U., Hsee, C. K., \& Welch, N. (2001). Risk as feelings. Psychological bulletin, 127(2), 267. 
MacKuen, M., Wolak, J., Keele, L., \& Marcus, G. E. (2010). Civic engagements: Resolute partisanship or reflective deliberation. American Journal of Political Science, 54(2), 440-458.

Marcus, G. E. (2000). Emotions in politics. Annual Review of Political Science, 3(1), 221250.

Marcus, G. E. (2010). Sentimental Citizen: Emotion in Democratic Politics: Penn State Press.

Möller, N. (2012). The concepts of risk and safety Handbook of risk theory (pp. 55-85): Springer.

Neuman, R., Marcus, G., Crigler, A., \& MacKuen, M. (2007). The affect effect. Dynamics of.

Nihlén Fahlquist, J., \& Roeser, S. (2014). Nuclear energy, responsible risk communication and moral emotions: a three level framework. Journal of Risk Research 18 (3), 333 346

Nussbaum, M. C. (2001). Upheavals of thought: The intelligence of emotions. Cambridge: Cambridge University Press.

Nussbaum, M. C. (2013). Political Emotions: Why Love Matters for Justice. Cambridge (MA): Harvard University Press.

O'Neill, J. (2002). The rhetoric of deliberation: Some problems in Kantian theories of deliberative democracy. Res Publica, 8(3), 249-268.

Owens, S., Rayner, T., \& Bina, O. (2004). New agendas for appraisal: reflections on theory, practice, and research. Environment and Planning A, 36(11), 1943-1960.

Pesch, U. (2005). The Predicaments of Publicness. An Inquiry into the Conceptual Ambiguity of Public Administration. Delft: Eburon.

Pesch, U. (2014). Sustainable development and institutional boundaries. Journal of Integrative Environmental Sciences, 11(1), 39-54.

Prichard, H. A. (1912). Does moral philosophy rest on a mistake? Mind, 21-37.

Ravetz, J. (1996). Scientific Knowledge and its Social Problems. New Brunswick \& London: Transaction Publishers.

Roberts, R. C. (2003). Emotions: An essay in aid of moral psychology. Cambridge: Cambridge University Press.

Roeser, S. (2006a). A particularist epistemology: 'affectual intuitionism'. Acta Analytica, 21(1), 33-44.

Roeser, S. (2006b). The role of emotions in judging the moral acceptability of risks. Safety Science, 44(8), 689-700. 
Roeser, S. (2009). The relation between cognition and affect in moral judgements about risks. In Asveld and Roeser (eds.), The Ethics of Technological Risk, London: Routledge/Earthscan, 182-201.

Roeser, S. (2010). Intuitions, emotions and gut reactions in decisions about risks: towards a different interpretation of 'neuroethics'. Journal of Risk Research, 13(2), 175-190.

Roeser, S. (2011). Nuclear energy, risk, and emotions. Philosophy \& Technology, 24(2), 197201.

Roeser, S. (2012). Risk communication, public engagement, and climate change: a role for emotions. Risk Analysis, 32(6), 1033-1040.

Rorty, R. (1989). Contingency, irony, and solidarity. Cambridge: Cambridge University Press.

Ross, W. D. (1939). Foundations of Ethics: The Gifford Lectures Delivered in the University of Aberdeen, 1935.

Rowe, G., \& Frewer, L. J. (2000). Public participation methods: A framework for evaluation. Science, Technology \& Human Values, 25(1), 3-29.

Scherer, K. R., Scherer, K. R., \& Ekman, P. (1984). On the nature and function of emotion: A component process approach. Approaches to emotion, 2293, 317.

Shrader-Frechette, K. (1991). Risk and Rationality: Philosophical Foundations for Populist Reforms. Berkeley: University of California Press.

Sloman, S. A. (1996). The empirical case for two systems of reasoning. Psychological bulletin, 119(1), 3.

Sloman, S. A. (2002). Two systems of reasoning. In T. Gillovich, D. Griffin \& D. Kahneman (Eds.), Heuristics and Biases. The Psychology of Intuitive Judgment (pp. 379-396). Cambridge: Cambridge University Press.

Slovic, P. (1999). Trust, emotion, sex, politics, and science: Surveying the risk-assessment battlefield. Risk Analysis, 19(4), 689-701.

Slovic, P. (2010a). The feeling of risk: New perspectives on risk perception. London and New York: Earthscan.

Slovic, P. (2010b). If I Look at the Mass I Will Never Act: Psychic Numbing and Genocide. In S. Roeser (Ed.), Emotions and risky technologies (pp. 37-59). Dordrecht, etc.: Springer. 
Slovic, P., Finucane, M. L., Peters, E., \& MacGregor, D. G. (2004). Risk as analysis and risk as feelings: Some thoughts about affect, reason, risk, and rationality. Risk Analysis, 24(2), 311-322.

Slovic, P. E. (2000). The perception of risk. London: Earthscan Publications.

Slovic, P. E., Finucane, M. L., Peters, E., \& MacGregor, D. G. (2002). The Affect Heuristic. In T. Gilovich, D. Griffin \& D. Kahneman (Eds.), Intuitive Judgment: Heuristics and Biases (pp. 397-420). Cambridge: Cambridge University Press.

Solomon, R. C. (1993). The passions: Emotions and the meaning of life. Indianapolis: Hackett Publishing.

Sousa, R. D. (1979). The rationality of emotions. Dialogue, 18(01), 41-63.

Staiger, J., Cvetkovich, A., \& Reynolds, A. (2010). Political emotions. London: Routledge.

Stanovich, K. E., \& West, R. F. (1998). Individual differences in rational thought. Journal of experimental psychology: general, 127(2), 161.

Stocker, M. (1996). Valuing emotions. Cambridge: Cambridge University Press.

Sunstein, C. R. (2005). Cost-Benefit Analysis and the Environment. Ethics, 115(2), 351-385.

Taylor, C. (1995). Philosophical arguments: Cambridge, Mass.: Harvard University Press.

Roeser, S. \& Todd, C. (eds.) (2014). Emotion and Value. Oxford: Oxford University Press.

Van Asselt, M. B., \& Rijkens-Klomp, N. (2002). A look in the mirror: reflection on participation in Integrated Assessment from a methodological perspective. Global Environmental Change, 12(3), 167-184.

Van de Kerkhof, M., \& Wieczorek, A. (2005). Learning and stakeholder participation in transition processes towards sustainability: Methodological considerations. Technological Forecasting and Social Change, 72(6), 733-747. doi: 10.1016/j.techfore.2004.10.002

Whewell, W. (1845). The elements of morality, including polity. London: John W. Parker.

Wynne, B. (1992). Misunderstood misunderstanding: social identities and public uptake of science. Public Understanding of Science, 1(3), 281-304. doi: 10.1088/0963$6625 / 1 / 3 / 004$

Zagzebski, L. (2003). Emotion and moral judgment. Philosophy and Phenomenological Research, 66(1), 104-124. 